\title{
Analytical Solution for the Steady-State Karst Water Inflow into a Tunnel
}

\author{
Han-song Xie, Chong Jiang $\mathbb{D}$, Jia-li He $\mathbb{D}$, and Hai-xia Han \\ School of Resources and Safety Engineering, Central South University, Changsha, 410083 Hunan, China \\ Correspondence should be addressed to Chong Jiang; jiang4107@sohu.com
}

Received 30 November 2018; Revised 29 December 2018; Accepted 13 January 2019; Published 25 February 2019

Guest Editor: Bisheng Wu

Copyright ( 2019 Han-song Xie et al. This is an open access article distributed under the Creative Commons Attribution License, which permits unrestricted use, distribution, and reproduction in any medium, provided the original work is properly cited.

\begin{abstract}
An analytical solution for the karst water inflow into a lined tunnel in an infinite plane is derived based on conformal mapping. The new solution considers the center distance between the tunnel and the cavern, the radii of the tunnel and the cavern, and the property of the lining, such as the permeability coefficient as well as the lining radius. Numerical models are established and calculated using the finite difference software FLAC3D to compare with the analytical solution of inversion transformation, and a good agreement is found. Then, the parameters of effect are discussed in detail. The results indicate that the karst water inflow shows a curve relationship as the radius of tunnel increase and increases as the lining becomes thinner or the permeability coefficient of the lining increases. Moreover, the pressure head decreases as the tunnel radius and the center distance between the tunnel and the cavern increase.
\end{abstract}

\section{Introduction}

Karst water inflow is a key issue affecting the construction and operating phases of drained tunnels [1]. Moreover, some researchers have determined that most tunnels eventually act as drains $[2,3]$. Therefore, analytical and numerical methods are the most commonly used methods to calculate the karst water inflow and pressure head of tunnels accurately.

Early researchers deduced analytical solutions for the water ingress into deeply buried tunnels. Lei [4] acquired an analytical solution for the steady flow into a deeply buried tunnel based on the image method. Conformal mapping could be used to investigate different boundary conditions along the tunnel circumference [5-9]. Ying et al. [10] derived an analytical solution for the groundwater ingress into a lined tunnel in a semi-infinite aquifer using the conformal mapping technique. In recent literature, Zhang [11] deduced an analytical solution for the seepage field of a parallel double-hole tunnel in a semi-infinite plane based on the seepage mechanics and image method. Some researchers used the theory of hydraulics and complex functions to solve the analytical solution for the groundwater inflow of surrounding rocks and lining structures [12-15]. Huang et al.
[16] validated these analytical solutions with the software FLAC3D. An analytical solution was given by Jiang et al. [17-19] regarding the seepage field in a water-filled karst tunnel based on the inversion of a complex function and groundwater hydraulics theory. The rate and potential distribution of the confined flow of ground water through an opening were obtained by Chisyaki [20] in connection with the permeability of rock masses, the thickness of covered ground, the location of impermeable bedrock, and other parameters. The analytical solution for the nonlinear consolidation of soft soil around a shield tunnel with idealized sealing linings was presented by Cao et al. [21]. An analytical solution for confined flow into a tunnel during progressive drilling was deduced by Perrochet $[22,23]$. Arjnoi et al. [24] solved the effect of drainage on pore water pressure distributions and lining stresses in drained tunnels.

However, most of the aforementioned literature have studied high hydraulic pressure tunnels or high hydraulic parallel tunnels in infinite plane. There are few analytical solutions for the karst water inflow and pressure head in karst tunnels. In this paper, a new analytical solution is derived for the steady-state karst water inflow into a circular tunnel with focus on the boundary condition of a pressure head of zero 


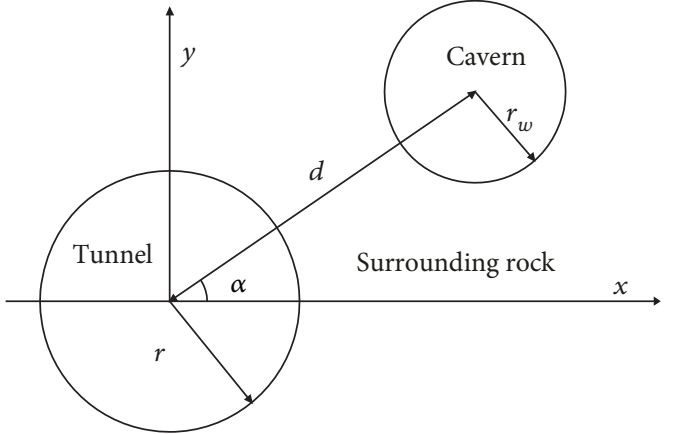

FIGURE 1: Schematic diagram of the karst tunnel in an infinite plane.

along the tunnel circumference based on conformal mapping. A numerical simulation is conducted to verify the solution. A parameter analysis, including the lining permeability and radius, the tunnel and cavern radii, and the center distance between the tunnel and the cavern, is discussed.

\section{Definition of the Problem}

2.1. Basic Assumptions. The simplified Naqiu Karst Tunnel [25-28] model takes the tunnel center as the origin, the horizontal direction as the $x$-axis, and the vertical direction as the $y$-axis to establish the coordinate system as shown in Figure 1. The expression of conformal mapping of a complex variable function is deduced by transforming elevation difference into angle $\alpha$ in the $x-y$ coordinate system, and then the expression of karst water seepage flow is solved. $\alpha$ is the angle between the $x$-axis and the line connecting the cave center to the tunnel center. The tunnel and the cavern with radii denoted as $r$ and $r_{w}$, respectively, are buried in an infinite aquifer. Here, $d$ is defined as the center distance between the tunnel and the cavern. The pressure head in the cavern is $H_{w}$, and the horizontal line across the tunnel center is chosen as the elevation reference datum. The pressure head in the tunnel is $H_{t}$. The coordinates of $\mathrm{A}, \mathrm{B}, \mathrm{C}, \mathrm{D}, \mathrm{E}$, and $\mathrm{F}$ are set as $(-r, 0),(0, r),(r, 0),\left(x_{1}, y_{1}\right),\left(x_{3}, y_{3}\right)$, and $\left(x_{2}, y_{2}\right)$, respectively, in Figure 2(a).

Additionally, the basic assumptions of this paper are as follows:

(1) The surrounding rock of the tunnel is homogeneous with isotropic permeability [6]

(2) The aquifer and karst water are incompressible. The flow is in a steady state and is governed by Darcy's law [4]

(3) The pore pressure is constant on the same circumference, the water-filling hole is equal to the pressure head, and the cavern is full of water $[10,17]$

2.2. Governing Equation. According to Darcy's law and mass conservation as well as the aforementioned assumptions, the steady-state karst water flow around the tunnel is described by the following Laplace equation [29]:

$$
\frac{\partial^{2} \phi}{\partial x^{2}}+\frac{\partial^{2} \phi}{\partial y^{2}}=0
$$

where $\phi$ is the total head, equal to the sum of pressure and elevation heads, as shown below:

$$
\phi=\frac{P}{\gamma_{w}}+y,
$$

where $P$ is the water pressure and $\gamma_{w}$ is the unit weight of water.

2.3. Boundary Conditions. Two boundary conditions along the tunnel and the cavern circumference are needed to solve equation (1). The boundary condition along the cavern circumference can be expressed as

$$
\phi_{\left(y_{1}=0\right)}=H_{\mathrm{w}} .
$$

In the case of constant total head, the boundary condition along the cavern circumference can be expressed as

$$
\phi_{\left(\left(x-\left(x_{1}+x_{2}\right) / 2\right)+\left(y-y_{1}\right)=r_{w}{ }^{2}\right)}=H_{\mathrm{t}} .
$$

\section{Analytical Solution}

3.1. The Solution for the Karst Water Inflow. The method of conformal mapping can facilitate the derivation of the pressure head and the karst inflow in this study. As shown in Figure 2, the tunnel and the cavern circumference in the $z$-plane can be mapped as two circles in the $w$-plane with radii $R_{0}$ and $R_{1}$, respectively, based on the complex mapping function in equation (5) $[30,31]$. The points $\mathrm{A}, \mathrm{B}, \mathrm{C}, \mathrm{D}, \mathrm{E}$, and $\mathrm{F}$ are mapped in the $w$-plane to obtain corresponding points $\mathrm{A}^{\prime}, \mathrm{B}^{\prime}, \mathrm{C}^{\prime}, \mathrm{D}^{\prime}, \mathrm{E}^{\prime}$, and $\mathrm{F}^{\prime}$ by conformal mapping method in Figure 2(b).

$$
R_{0}=\frac{1-A}{1+A}
$$

where $R_{0}$ is the radius of tunnel mapping circle in the $w$-plane. $\quad A=\left(\left(x_{1}+i y_{1}-r\right) /\left(x_{1}+i y_{1}+r\right)\right) \cdot\left(\left(x_{2}+i y_{2}+r\right) /\right.$ $\left.\left(x_{2}+i y_{2}-r\right)\right)$, and $r$ is the tunnel radius.

It is assumed that both $\mathrm{y}_{1}$ and $\mathrm{y}_{2}$ are equal to zero without loss of generality for simplicity. Thus, equation (5) can be expressed as

$$
R_{0}=\frac{x_{2} x_{1}-r^{2}-\sqrt{\left(x_{1}^{2}-r^{2}\right)\left(x_{2}^{2}-r^{2}\right)}}{\left(x_{2}-x_{1}\right) r}, \quad 0<R_{0}<1 .
$$

Expression of $w$ in the $w$-plane when $y_{1}=0$ and $y_{2}=0$ is as follows:

$$
w=R_{0} \frac{(\mathrm{z}-\mathrm{r})\left(x_{2}+r\right)\left(1-R_{0}\right)+(z+r)\left(x_{1}-r\right)\left(1+R_{0}\right)}{(z+r)\left(x_{1}-r\right)\left(1+R_{0}\right)-(\mathrm{z}-\mathrm{r})\left(x_{2}+r\right)\left(1-R_{0}\right)},
$$




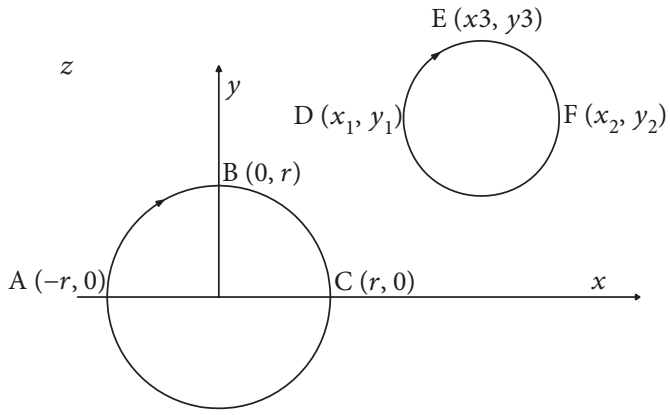

(a)

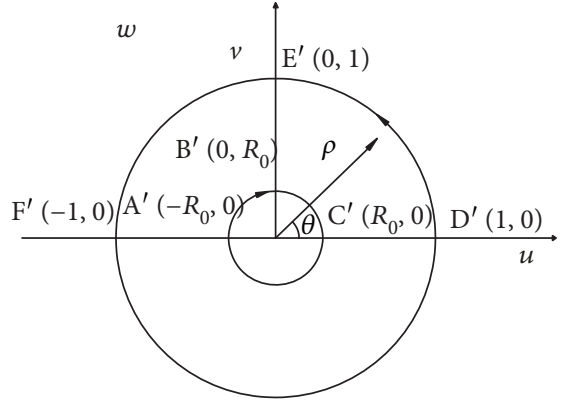

(b)

Figure 2: Conformal mapping.

where $z=x+i y$, which is the complex variable function of $z$ in the $z$-plane. $w=u+i v=f(z)$, which is the complex variable function of $w$ in the $w$-plane.

Then, equation (1) can be rewritten in terms of coordinate $u-v$ :

$$
\frac{\partial^{2} \phi}{\partial u^{2}}+\frac{\partial^{2} \phi}{\partial v^{2}}=0
$$

By considering the boundary conditions, the solution for total head on a circle with radius $\rho$ in the $w$-plane can be obtained as

$$
\phi=C_{1}+C_{2} \ln \rho+\sum_{n=1}^{\infty}\left(C_{3} \rho^{n}+C_{4} \rho^{-n}\right) \cos n \theta
$$

where $C_{1}, C_{2}, C_{3}$, and $C_{4}$ are determined by the boundary conditions along the tunnel and the cavern circumference. $n$ is the natural number in the series, and $\theta$ is the angle between $\rho$ and the $u$-axis in the $w$-plane. $\rho$ is a radius variable between the tunnel and karst cave mapping circle in the $w$-plane, and $R_{0} \leq \rho \leq 1$.

The constant $C_{1}$ can be expressed by considering the boundary condition along the cavern circumference with $\rho=1$ in the $w$-plane while the constant $C_{2}$ can be obtained by considering the boundary conditions along the tunnel and the cavern circumference with $\rho=R_{0}$ in the $w$-plane.

$$
\begin{aligned}
\phi(\rho=1) & =C_{1}+\sum_{n=1}^{\infty}\left(C_{3}+C_{4}\right) \cos n \theta \\
& =H_{w} \rightarrow C_{1}=H_{w}, \quad C_{3}=-C_{4}=0, \\
\phi\left(\rho=R_{0}\right) & =C_{1}+C_{2} \ln R_{0}+\sum_{n=1}^{\infty}\left(C_{3} R_{0}{ }^{n}+C_{4} R_{0}{ }^{-n}\right) \cos n \theta \\
& =H_{\mathrm{t}} \rightarrow C_{2}=\frac{H_{\mathrm{t}}-H_{\mathrm{w}}}{\ln R_{0}}, \quad C_{3}=0 .
\end{aligned}
$$

Thus,

$$
\phi=H_{t}+\frac{H_{t}-H_{w}}{\ln R_{0}} \ln \rho,
$$

where $H_{t}$ is the pressure head of the tunnel.

The solution for the karst water inflow, which is the volume of water per unit tunnel length, into a drained circular tunnel can be obtained for the constant total head as

$$
Q=k \int_{0}^{2 \pi} \frac{\partial \phi}{\partial \rho} \rho d \rho=2 \pi k \frac{H_{t}-H_{w}}{\ln R_{0}},
$$

where $Q$ is the karst water inflow; $k$ is the permeability coefficients of the surrounding rock.

$y_{1}=0$ and $y_{2}=0$; thus, $x_{1}=d-r_{w}, x_{2}=d+r_{w}$, and $x_{1}$ $-x_{2}=-2 r_{w}$; equations (6) and (12) can be rewritten as equations (13) and (14), respectively:

$R_{0}=\frac{d^{2}-r_{w}^{2}-r^{2}-\sqrt{\left(\left(d+r_{w}\right)^{2}-r^{2}\right)\left(\left(d-r_{w}\right)^{2}-r^{2}\right)}}{2 r r_{w}}$,

$Q=2 \pi k \frac{H_{t}-H_{w}}{\ln \left(\left(d^{2}-r_{w}^{2}-r^{2}-\sqrt{\left(\left(d+r_{w}\right)^{2}-r^{2}\right)\left(\left(d-r_{w}\right)^{2}-r^{2}\right)}\right) / 2 r r_{w}\right)}$.

The expression of $w_{2}$ with $\alpha$ in the $w$-plane is as follows:

$$
w_{2}=\frac{w_{1}-r A_{1}}{w_{1} A_{1}-r}
$$

where $\quad w_{1}=-e^{i \alpha} z \quad$ and $\quad A_{1}=\left(d^{2}+r^{2}-r_{w}^{2}+\right.$ $\left.\sqrt{r^{4}+\left(d^{2}-r_{w}^{2}\right)^{2}-2\left(d^{2}+r_{w}^{2}\right)}\right) / 2 d r$.

3.2. The Solution for the Pressure Head of the Lining Structure. The pressure head along the lining and grouting circumference cannot be solved by the complex function, but it can be solved by using the groundwater seepage mechanics and the theory of infinite aquifer shaft [12]. The 


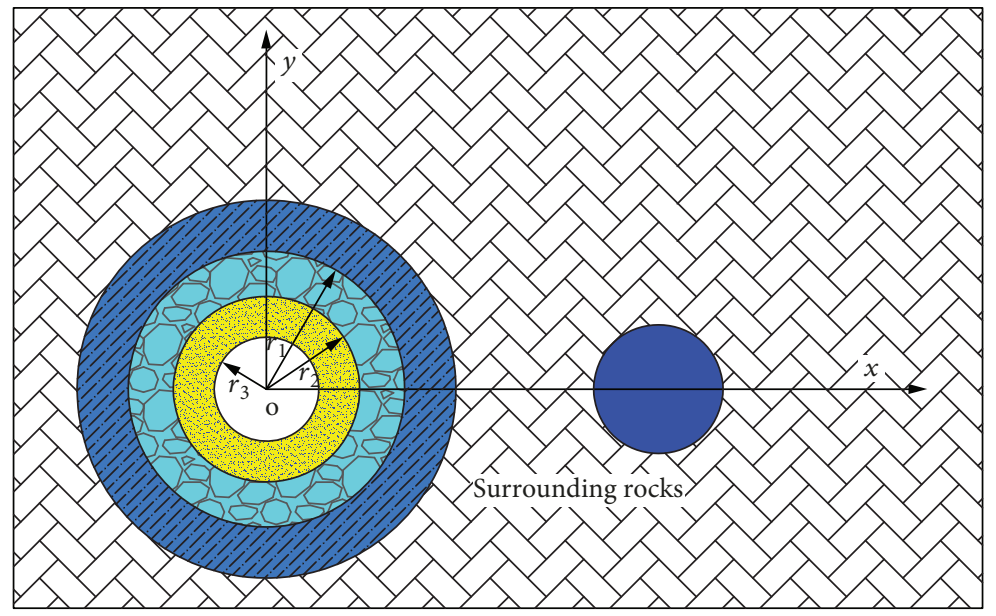

Cavern

Secondary lining

E Initial support

E:1 Grouting circle

FIgURE 3: The relationships between each lining structure.

pressure head of relationships between the initial support, the secondary lining, and the grouting circle are expressed as equations (16), (17), and (18) and shown in Figure 3:

$$
\begin{aligned}
& H_{t}-H_{1}=\frac{Q}{2 \pi k_{1}} \ln \frac{r}{r_{1}}, \\
& H_{1}-H_{2}=\frac{Q}{2 \pi k_{2}} \ln \frac{r_{1}}{r_{2}}, \\
& H_{2}-H_{3}=\frac{Q}{2 \pi k_{3}} \ln \frac{r_{2}}{r_{3}},
\end{aligned}
$$

where $H_{1}, H_{2}$, and $H_{3}$ are the pressure head along the joints of the grouting circle and initial support circumference, the initial support and the secondary lining circumference, and the secondary lining inner circumference, respectively; $r_{1}$, $r_{2}$, and $r_{3}$ are the radii of the grouting circle, initial support, and internal of secondary lining, respectively; and $k_{1}, k_{2}$, and $k_{3}$ are the permeability coefficients of the grouting circle, initial support, and secondary lining, respectively.

According to different phases of construction such as tunnel excavation and grouting, different distributions of pressure head can be obtained. When the grouting circle, initial support, and two linings are completed, the karst water inflow in the tunnel is

$Q=\frac{2 \pi\left(H_{w}-H_{3}\right)}{\left(1 / k_{2}\right) \ln \left(r_{1} / r_{2}\right)+\left(1 / k_{1}\right) \ln \left(r / r_{1}\right)+\left(1 / k_{3}\right) \ln \left(r_{2} / r_{3}\right)-(1 / k) \ln \left(R_{0}\right)}$.

The pressure head of the circumference of the initial support and secondary lining joint is as follows:

$$
H_{2}=H_{3}+\frac{H_{w}-H_{3}}{k_{3} A} \ln \frac{r_{2}}{r_{3}} .
$$

The pressure head of the circumference of the grouting circle and initial support joint is as follows:

$$
H_{1}=H_{3}+\frac{H_{w}-H_{3}}{k_{3} A} \ln \frac{r_{2}}{r_{3}}+\frac{H_{w}-H_{3}}{k_{2} A} \ln \frac{r_{1}}{r_{2}},
$$

where $A=\left(1 / k_{2}\right) \ln \left(r_{1} / r_{2}\right)+\left(1 / k_{1}\right) \ln \left(r / r_{1}\right)+\left(1 / k_{3}\right) \ln \left(r_{2} /\right.$ $\left.r_{3}\right)-(1 / k) \ln R_{0}$.

When the tunnel grouting and initial support are completed, the karst water inflow in the tunnel is

$$
Q=\frac{2 \pi\left(H_{w}-H_{2}\right)}{\left(1 / k_{2}\right) \ln \left(r_{1} / r_{2}\right)+\left(1 / k_{1}\right) \ln \left(r / r_{1}\right)-(1 / k) \ln R_{0}}
$$

The pressure head of the circumference of the grouting circle and initial support joint is as follows:

$$
H_{1}=H_{2}+\frac{\left(H_{w}-H_{2}\right) \ln \left(r_{1} / r_{2}\right)}{\ln \left(r_{1} / r_{2}\right)+\left(k_{2} / k_{1}\right) \ln \left(r / r_{1}\right)-\left(k_{2} / k\right) \ln R_{0}} .
$$

\section{Verification and Discussion}

Analytical solutions for the karst water inflow and the pressure head are deduced, and thus, it is necessary to verify them. In the following section, the numerical solution simulated by the finite difference software FLAC3D and the theoretical solution deduced by Jiang et al. [17] are compared with the theoretical solution obtained by the conformal mapping method used in this paper.

4.1. Numerical Verification. The main calculation conditions are shown in Table 1 , and the model of $100 \times 100 \mathrm{~m}$ is established with FLAC3D. According to the difference of $d$, the model is divided into 6 groups, each of which sets up 20 
TABLE 1: Characteristic data for verification.

\begin{tabular}{lc}
\hline Characteristic & Value \\
\hline The pressure head of the cavern $H_{w}$ & $54 \mathrm{~m}$ \\
The radius of the tunnel $r$ & $7.25 \mathrm{~m}$ \\
The radius of the cavern $r_{w}$ & $4 \mathrm{~m}$ \\
The radius of the grouting circle $r_{1}$ & $2.25 \mathrm{~m}$ \\
The initial support radius $r_{2}$ & $2 \mathrm{~m}$ \\
Permeability coefficient of surrounding rocks $k$ & $1.5 \times 10^{-6} \mathrm{~cm} \cdot \mathrm{s}^{-1}$ \\
Permeability coefficient of grouting circle $k_{1}$ & $10^{-7} \mathrm{~cm} \cdot \mathrm{s}^{-1}$ \\
Permeability coefficient of initial support $k_{2}$ & $10^{-8} \mathrm{~cm} \cdot \mathrm{s}^{-1}$ \\
\hline
\end{tabular}

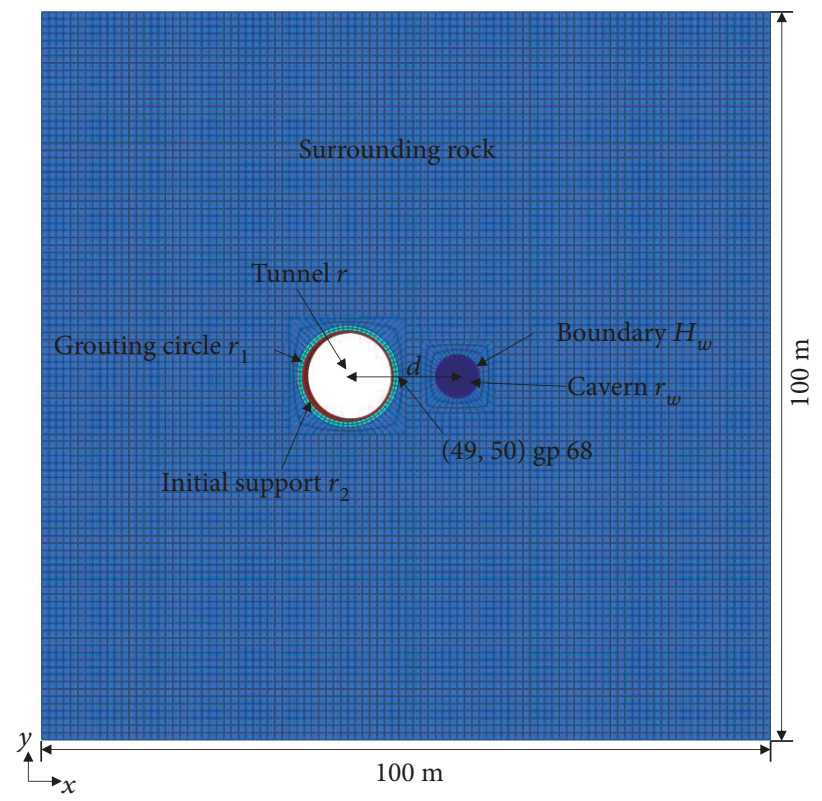

FIGURE 4: Finite element model of the circular karst tunnel.

models according to the difference of $r$ and $r_{w}$. Then, the pore water pressure of the tunnel considering gravity and without considering gravity are obtained, respectively. When $d=15 \mathrm{~m}$, the karst tunnel model consists of 33456 elements, as shown in Figure 4.

During the numerical simulation, the pore water pressure was measured at 4 points at the top, bottom, and both sides of the tunnel after excavation, initial support, and grouting, respectively. For example, the coordinates of the monitoring point on the right side of tunnel is $(49,50)$ and the node number is 68 in Figure 4 . The pore water pressure considering gravity is $473662 \mathrm{~Pa}$ when the tunnel is stable, while the pore water pressure without considering gravity is $468681 \mathrm{~Pa}$. The values of corresponding points can be obtained in the contour of pore water pressure, as shown in Figures 5 and 6.

4.2. Theoretical Comparison. According to different phases of construction such as tunnel excavation and grouting, different distributions of pressure head can be obtained based on the inversion of complex functions [17]. When tunnel
Contour of zone pore pressure

Calculated by: volumetric averaging

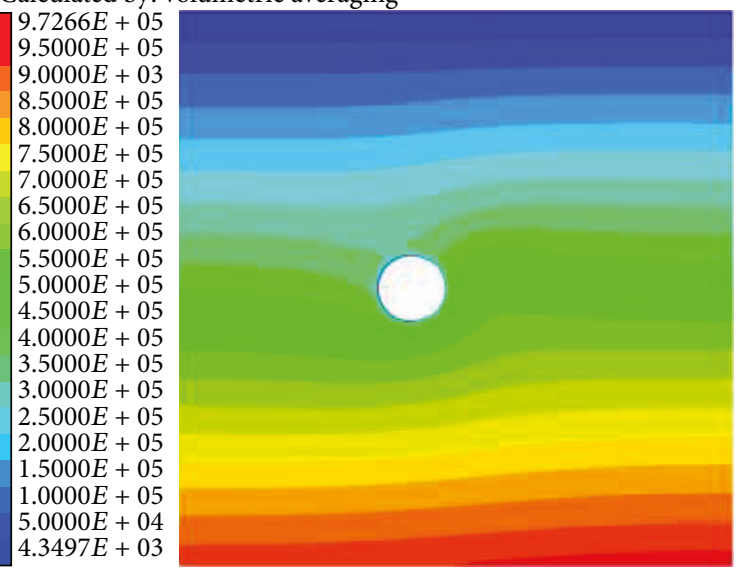

FIGURE 5: Contour of pore water pressure considering gravity for $d=15, r=7$, and $r_{w}=4$.

Contour of zone pore pressure

Calculated by: volumetric averaging

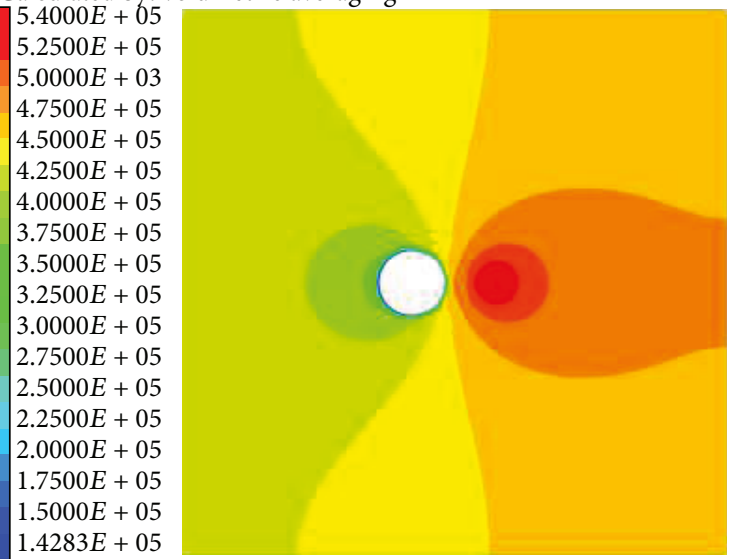

FIgURE 6: Contour of pore water pressure without considering gravity for $d=15, r=7$, and $r_{w}=4$.

grouting and initial support are completed, the karst water inflow in the tunnel is

$$
Q=\frac{2 \pi\left(H_{w}-H_{2}\right)}{\left(1 / k_{2}\right) \ln \left(r_{1} / r_{2}\right)+\left(1 / k_{1}\right) \ln \left(r / r_{1}\right)+(1 / k) \ln \left(\left(d^{2}-\mathrm{r}^{2}\right) / r r_{w}\right)}
$$

The pressure head of the grouting circle and initial support joint is as follows:

$H_{1}=H_{2}+\frac{\left(H_{w}-H_{2}\right) \ln \left(r_{1} / r_{2}\right)}{\ln \left(r_{1} / r_{2}\right)+\left(k_{2} / k_{1}\right) \ln \left(r / r_{1}\right)+\left(k_{2} / k\right) \ln \left(\left(d^{2}-r^{2}\right) / r r_{w}\right)}$.

The solution of conformal mapping, the solution of inversion transformation, and the numerical solution are compared under the conditions of Table 1, as shown in Figure 7. It was found from the comparison of numerical solution and theoretical solution that when the grouting ring 


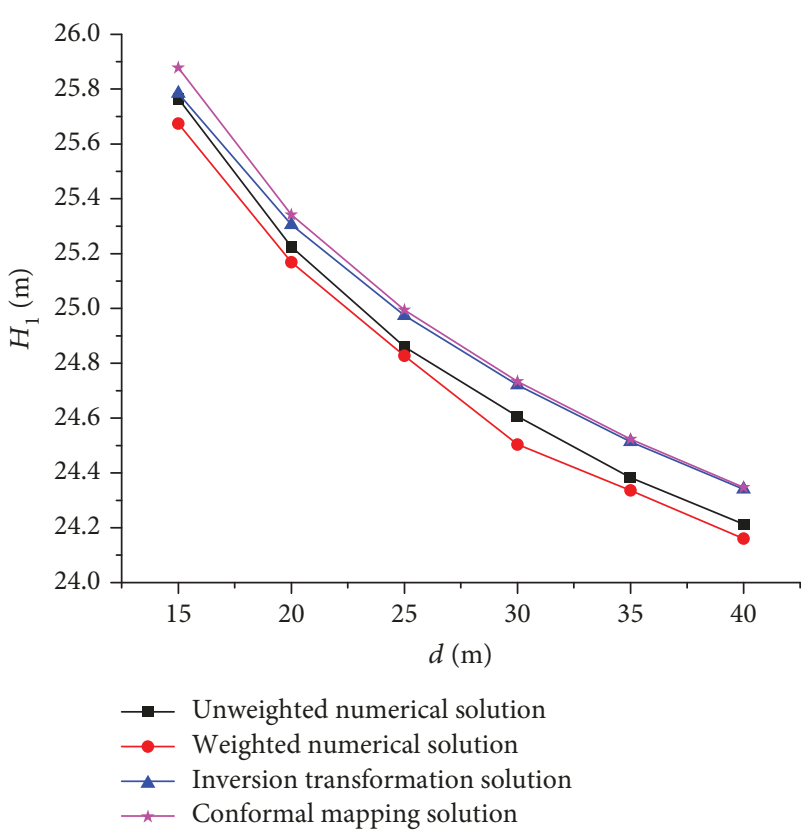

Figure 7: Comparison of numerical solution and theoretical solution for $r=7.25$ and $r_{w}=4$.

and the initial support are completed and the secondary lining is not yet completed, $H_{1}$ decreases with the increase of $d$. When $d=15 \mathrm{~m}, H_{1}$ for the theoretical solution, inversion transformation solution, numerical solution considering gravity, and numerical solution without considering gravity are $25.78 \mathrm{~m}, 25.88 \mathrm{~m}, 25.67 \mathrm{~m}$, and $25.77 \mathrm{~m}$, respectively. Therefore, the analytical method in this paper is suitable for solving the distribution of seepage field in karst tunnels. In general, a good agreement between the two methods and simulations could be obtained from the comparison.

\section{Discussion}

The equations (13)-(23) indicate that the parameters affecting karst water inflow into the tunnel include the pressure head of cavern, $H_{w}$; the center distance between the tunnel and the cavern, $d$; the radii of the cavern, grouting circle and initial support, $r_{w}, r_{1}$, and $r_{2}$, respectively; and the permeability coefficients of surrounding rocks, grouting circle, and initial support, $k, k_{1}$, and $k_{2}$, respectively.

5.1. The Effect of Center Distance and Cavern Radius. In this part, the center distance between the tunnel and the cavern $d$ varies from 11.5 to $49.5 \mathrm{~m}$, while the other parameters remain the same as those listed in Table 1 . Figure 8 indicates that $H_{1}$ gradually decreases as $d$ increases. Moreover, in the case of $k_{r}=k / k_{1}=10$, pressure head decreases $3.76 \mathrm{~m}$ from $d=11.5$ $\mathrm{m}$ to $d=49.5 \mathrm{~m}$ and the values are $2 \mathrm{~m}, 0.61 \mathrm{~m}$, and $0.2 \mathrm{~m}$, respectively, in the case of $k_{r}=20,50$, and 100. The slope becomes smaller as $d$ increases, which means the influence of $d$ on $H_{1}$ gradually decreases and tends to be stable. This demonstrates that the effect of center distance between the tunnel and the cavern on the pressure head of the grouting circle is obvious when the distance is short.

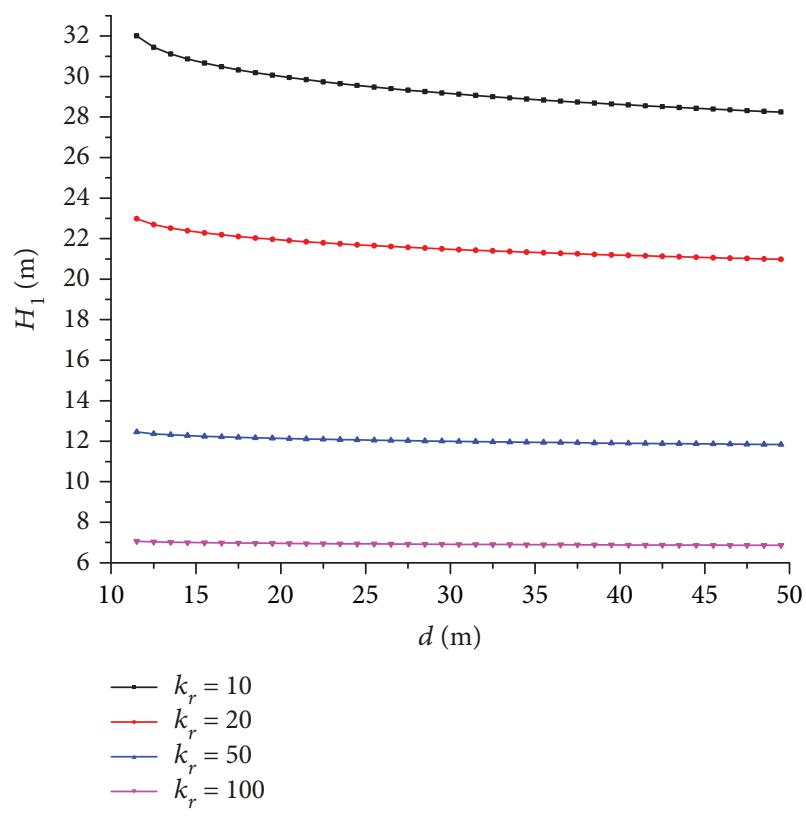

FIGURE 8: Relationship between the head pressure and distance.

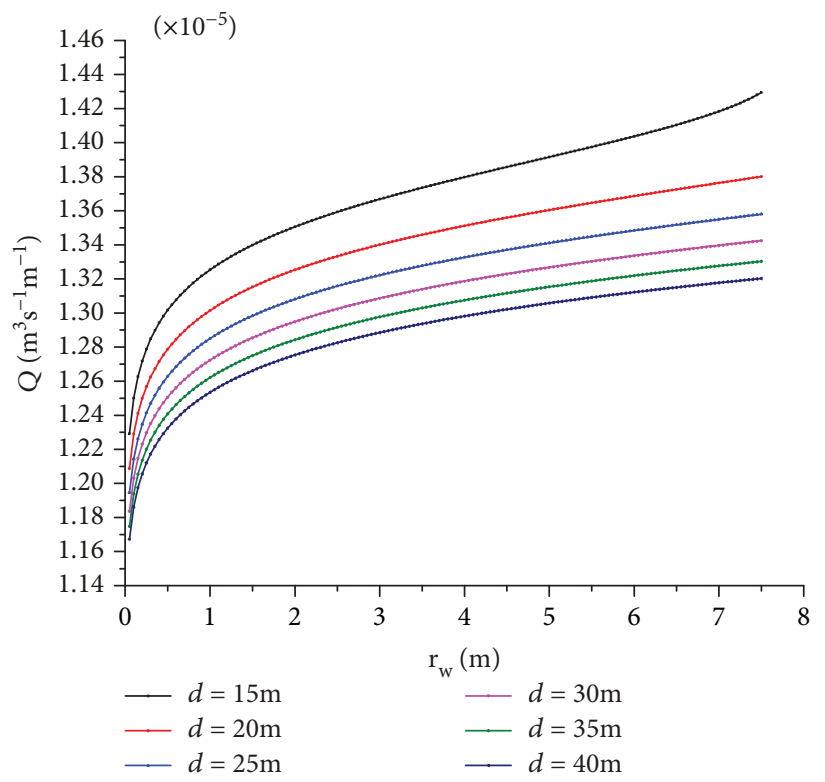

FIGURE 9: Relationship between the karst water flow and cavern radius.

Figure 9 illustrates the relationship between karst water inflow and cavern radius with different $d$. With the increase of $r_{w}$, the karst water inflow gradually increases and the change rate gradually decreases to a stable state. This means the effect of the cavern radius on the tunnel water inflow is obvious when the radius is increasing, and thus, the block effect of the lining should not be ignored in terms of water ingress estimate.

5.2. The Effect of the Grouting Circle. Figure 10 illustrates the relationship between pressure head and tunnel radius with 


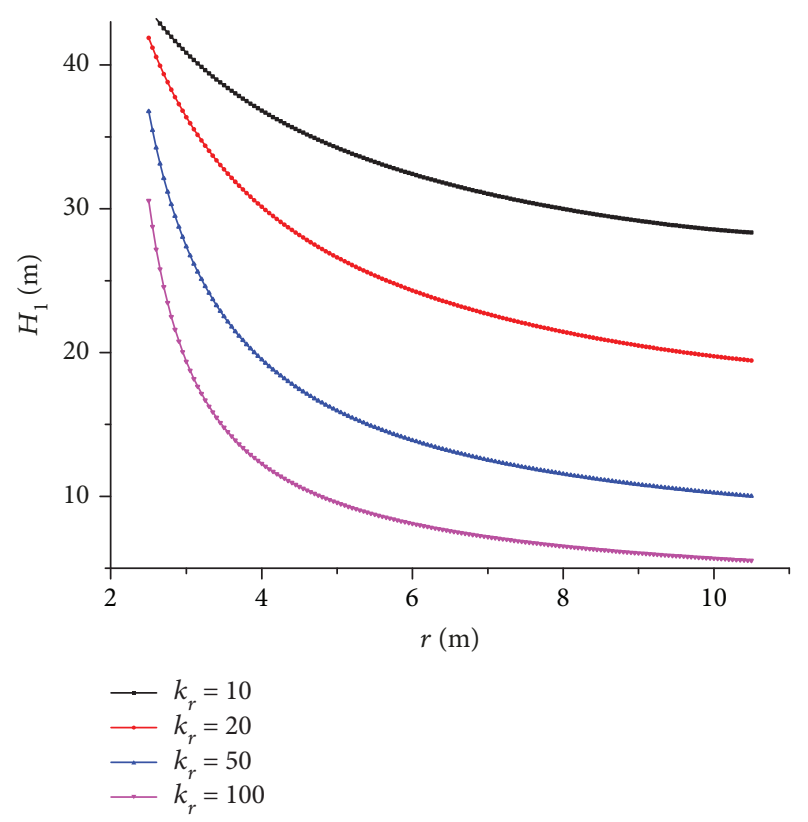

FIGURE 10: Relationship between the pressure head and tunnel radius.

different $d$. As $r$ increases, $H_{1}$ gradually decreases. Moreover, in the case of $k_{r}=10$, the pressure head decreases by $7.08 \mathrm{~m}$ from $r=2.5 \mathrm{~m}$ to $r=4 \mathrm{~m}$ accounting for $45.5 \%$ of the total reduction which is $15.56 \mathrm{~m}$ from $r=2.5 \mathrm{~m}$ to $r=10.5 \mathrm{~m}$. And when $r=10.5 \mathrm{~m}$, the reductions of the pressure head are $22.43 \mathrm{~m}, 26.76 \mathrm{~m}$, and $25.03 \mathrm{~m}$, respectively, in the case of $k_{r}=20,50$, and 100 . When $r=4 \mathrm{~m}$, the reductions of the pressure head are $11.74 \mathrm{~m}, 17.27 \mathrm{~m}$, and $18.29 \mathrm{~m}$ accounting for $52.3 \%, 64.5 \%$, and $73.1 \%$ of the total reduction, respectively. When $r>4 \mathrm{~m}$, the reduction rate of $H_{1}$ decreases linearly and gradually slows down. When $r<4 \mathrm{~m}$, the reduction rate of $H_{1}$ is faster than that of $r>4 \mathrm{~m}$. Figure 11 illustrates the relationship between the karst water inflow and permeability coefficient of the grouting circle. With the increase of $k_{r}$, the karst water inflow gradually decreases and tends to be stable. In addition, the curves for different $d$ in Figure 11 gradually overlap, which means the influence of $d$ on $Q$ is gradually reduced.

5.3. The Effect of Initial Support. Figure 12 illustrates the relationship between the pressure head and radius of the grouting circle for different $d$. Increasing $r_{1}$ means increasing the thickness of the initial support and reducing the thickness of the grouting circle. With the increase of $r_{1}, H_{1}$ gradually increases, and the curves for different $d$ in Figure 12 almost coincide, indicating that $d$ has little influence on $H_{1}$ when $r_{1}$ remains unchanged.

As shown in Figure 13, $Q$ increases with increase of $k_{2}$. Moreover, in the case of $k r=10$, the karst water inflow increases by $27.6 \times 10^{-6} \mathrm{~m}^{2} \mathrm{~s}^{-1}$ from $k_{2}=2.5 \times 10^{-9} \mathrm{~ms}^{-1}$ to $k_{2}=10^{-7} \mathrm{~ms}^{-1}$ and increases by $16.243 \times 10^{-6} \mathrm{~m}^{2} \mathrm{~s}^{-1}$ from $k_{2}=2.5 \times 10^{-9} \mathrm{~ms}^{-1}$ to $k_{2}=2 \times 10^{-8} \mathrm{~ms}^{-1}$, accounting for $58.85 \%$ of the total growth. When the other conditions are kept the same, the change of the initial support permeability

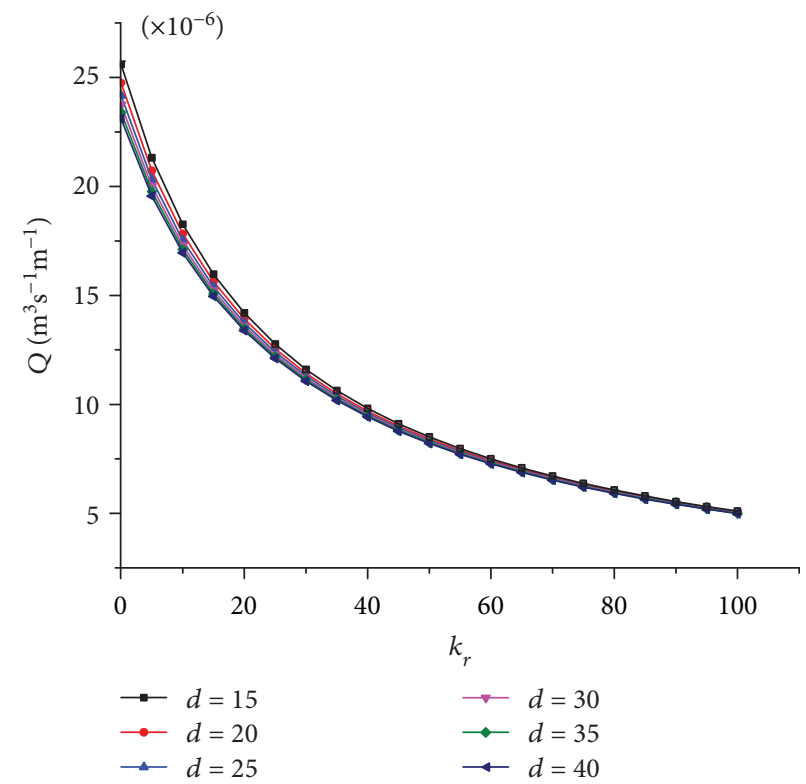

FIgURE 11: Relationship between the karst water inflow and permeability coefficient of the grouting circle.

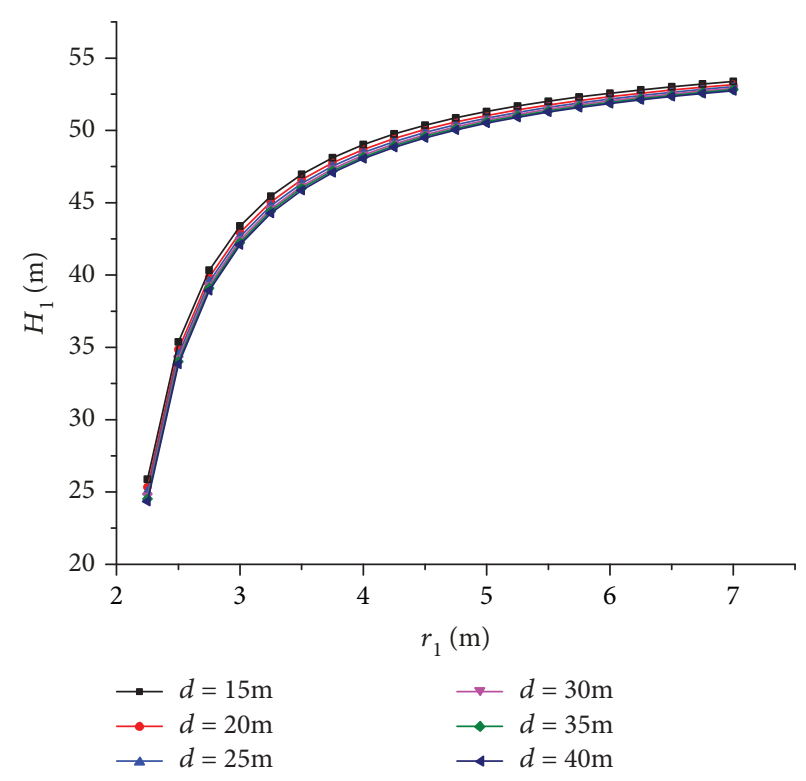

FIGURE 12: Relationship between the pressure head and radius of the grouting circle.

coefficient has an impact on karst water flow at $10^{-8}$ magnitude, while it has a greater impact at $10^{-9}$ magnitude with a higher cost. On the other hand, for a sealed tunnel, once the waterproof facilities failed, the karst water inflow would increase dramatically.

\section{Conclusion}

This paper derived analytical solutions for the steady-state karst water inflow and verified the new solution with 


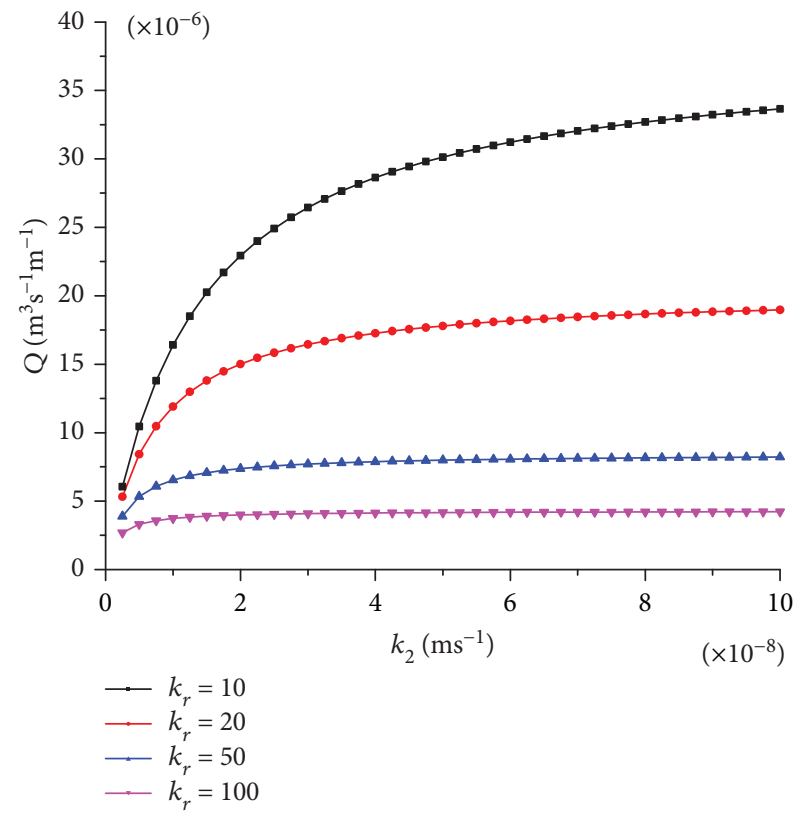

FIGURE 13: Relationship between the karst water flow and permeability coefficient of the grouting circle.

numerical simulation and analytical solution. The conclusions from this study are summarized as follows:

(1) The expression of karst water seepage flow in the karst tunnel is derived by conformal mapping method and then verified with numerical simulation via the software FLAC3D and analytical solution obtained from the method of inversion transformation

(2) The karst water inflow shows a curve relationship as the tunnel radius increase and increases as the lining becomes thinner or the permeability coefficient of the lining increases. For a sealed tunnel, once the waterproof facilities failed, the karst water inflow would increase dramatically. During construction, we should pay attention to the safety range of the initial support thickness

(3) When the other parameters remain unchanged, $H_{1}$ decreases and becomes stable as $d$ increases. When $r>4 \mathrm{~m}$, the reduction rate of $H_{1}$ decreases linearly and gradually slows down. When $r<4 \mathrm{~m}$, the reduction rate of $H_{1}$ is faster than that of $r>4 \mathrm{~m}$. When $r=4 \mathrm{~m}$, the decrease of $H_{1}$ with the increase of $k_{r}$ gradually increases. With the increase of $r_{1}, H_{1}$ gradually increases, and the curves for different $d$ almost coincide, indicating that $d$ has little influence on $H_{1}$ when $r_{1}$ remains unchanged

(4) The model assumed in this paper has some limitations. There is no surface water on the ground, so the inflow and pressure head of the surface water are not taken into account in the simplified model. Therefore, the inflow and pressure head models of seepage field under the interaction of the surface water and karst water are required for further research

\section{Data Availability}

The data used to support the findings of this study are available from the corresponding author upon request.

\section{Conflicts of Interest}

The authors declare that there are no conflicts of interest regarding the publication of this paper.

\section{Acknowledgments}

This work is supported by the National Natural Science Foundation of China (Grant Nos. 51678570 and 51478479) and Hunan Transport Technology Project (Grant No. 201524).

\section{References}

[1] Y. Zhao, F. Wang, C. Li, Y. Cao, and H. Tian, "Study of the corrosion characteristics of tunnel fissures in a karst area in Southwest China," Geofluids, vol. 2018, 19 pages, 2018.

[2] J. H. Atkinson and R. J. Mair, "Loads on leaking and watertight tunnel linings, sewers and buried pipes due to groundwater," Géotechnique, vol. 33, no. 3, pp. 341-344, 1983.

[3] J. Wongsaroj, K. Soga, and R. J. Mair, "Modelling of long-term ground response to tunnelling under St James's Park, London," Geotechnique, vol. 57, no. 1, pp. 75-90, 2007.

[4] S. Lei, "An analytical solution for steady flow into a Ttonnel," Groundwater, vol. 37, no. 1, pp. 23-26, 1999.

[5] K. H. Park, A. Owatsiriwong, and J. G. Lee, "Analytical solution for steady-state groundwater inflow into a drained circular tunnel in a semi-infinite aquifer: a revisit," Tunnelling and Underground Space Technology, vol. 23, no. 2, pp. 206209, 2008

[6] J. G. Wu, A Coupled Fluid-Mechanical Study on Seepage Field of Tunnels with High Hydraulic Pressure, Beijing Jiaotong University, 2006.

[7] M. El Tani, "Water inflow into tunnels," in Proceedings of the Word Tunnel Congress ITA-AITES, pp. 61-70, Oslo, 1999, Balkema.

[8] C. Butscher, "Steady-state groundwater inflow into a circular tunnel," Tunnelling and Underground Space Technology, vol. 32, no. 6, pp. 158-167, 2012.

[9] H. Zhu, J. Shen, F. Zhang et al., "DEM-CFD modeling of proppant pillar deformation and stability during the fracturing fluid flowback," Geofluids, vol. 2018, Article ID 3535817, 18 pages, 2018.

[10] H. W. Ying, C. W. Zhu, H. W. Shen, and X. N. Gong, "Semi-analytical solution for groundwater ingress into lined tunnel," Tunnelling and Underground Space Technology, vol. 76, pp. 43-47, 2018.

[11] B. Q. Zhang, "Analytical solution for seepage field of twin-parallel tunnel in semi-infinite plane," Journal of The China Railway Society, vol. 39, no. 1, pp. 125-131, 2017.

[12] C. W. Du, M. S. Wang, and Z. S. Tan, "Analytic solution for seepage field of subsea tunnel and its application," Chinese 
Journal of Rock Mechanics and Engineering, vol. 30, no. s2, pp. 3567-3573, 2011.

[13] L. Tong, K. H. Xie, M. M. Lu, and K. Wang, "Analytical study of seepage flow into a lined tunnel in a semi-infinite aquifer," Rock and Soil Mechanics, vol. 32, no. 1, pp. 304-308, 2011.

[14] F. Zhang, Y. Fang, D. Elsworth, C. Wang, and X. Yang, "Evolution of friction and permeability in a propped fracture under shear," Geofluids, vol. 2017, Article ID 2063747, 13 pages, 2017.

[15] B. Wu, T. Ma, G. Feng, Z. Chen, and X. Zhang, "An approximate solution for predicting the heat extraction and preventing heat loss from a closed-loop geothermal reservoir," Geofluids, vol. 2017, Article ID 2041072, 17 pages, 2017.

[16] F. M. Huang, Z. S. Tan, M. S. Wang, and X. Wang, "Analytical solution for water inflow into an underwater tunnel and its application," Engineering Sciences, vol. 11, no. 7, pp. 3 568-3 573, 2009.

[17] C. Jiang, H. S. Xie, J. L. He, W. Y. Wu, and Z. C. Zhang, "Analytical solution of seepage field in karst tunnel," Advances in Civil Engineering, vol. 2018, Article ID 9215472, 9 pages, 2018.

[18] C. Jiang, Y. Li, L. Liu, and H. Lin, "Nonlinear analysis of flexible pile near undrained clay slope under lateral loading," Advances in Civil Engineering, vol. 2018, Article ID 6817362, 13 pages, 2018.

[19] C. Jiang, L. Lin, C. Li, T. B. Li, and J. He, "The undrained vertical and horizontal bearing capacity of internal skirted foundation in clay," European Journal of Environmental and Civil Engineering, pp. 1-18, 2018.

[20] T. Chisyaki, "A study on confined flow of ground water through a tunnel," Groundwater, vol. 22, no. 2, pp. 162-167, 2010.

[21] Y. Cao, J. Jiang, K. H. Xie, and W. M. Huang, "Analytical solutions for nonlinear consolidation of soft soil around a shield tunnel with idealized sealing linings," Computers and Geotechnics, vol. 61, pp. 144-152, 2014.

[22] P. Perrochet, "Confined flow into a tunnel during progressive drilling: an analytical solution," Ground Water, vol. 43, no. 6 , pp. 943-946, 2005.

[23] P. Perrochet, "A simple solution to tunnel or well discharge under constant drawdown," Hydrogeology Journal, vol. 13, no. 5-6, pp. 886-888, 2005.

[24] P. Arjnoi, J. H. Jeong, C. Y. Kim, and K. H. Park, "Effect of drainage conditions on porewater pressure distributions and lining stresses in drained tunnels," Tunnelling and Underground Space Technology, vol. 24, no. 4, pp. 376-389, 2009.

[25] H. W. Chen and C. Sha, "Stability analysis of surrounding rock and treatment structures in superlarge karst cave of Naqiu tunnel," Advances in Civil Engineering, vol. 2018, Article ID 4842308, 14 pages, 2018.

[26] C. Jiang, J. L. He, L. Liu, and B. W. Sun, "Effect of loading direction and slope on laterally loaded pile in sloping ground," Advances in Civil Engineering, vol. 2018, Article ID 7569578, 12 pages, 2018.

[27] H. Lin, H. Wang, X. Fan, P. Cao, and K. Zhou, "Particle size distribution effects on deformation properties of graded aggregate base under cyclic loading," European Journal of Environmental and Civil Engineering, pp. 1-18, 2017.

[28] X. Fan, H. Lin, H. Lai, R. Cao, and J. Liu, "Numerical analysis of the compressive and shear failure behavior of rock containing multi-intermittent joints," Comptes Rendus Mécanique, vol. 347, no. 1, pp. 33-48, 2019.
[29] M. Y. Zhang, S. R. Jing, and G. J. Li, Higher Engineering Fluid Dynamics, Higher Education Press, 2012.

[30] A. Verruijt, Complex Variable Solutions of Elastic Tunneling Problems, Rapport COB 96-04, 1996.

[31] A. Verruijt and J. R. Booker, "Complex variable analysis of Mindlin's tunnel problem," in Development of Theoretical Geomechanics, pp. 3-22, Balkema, Sydney, 2000. 

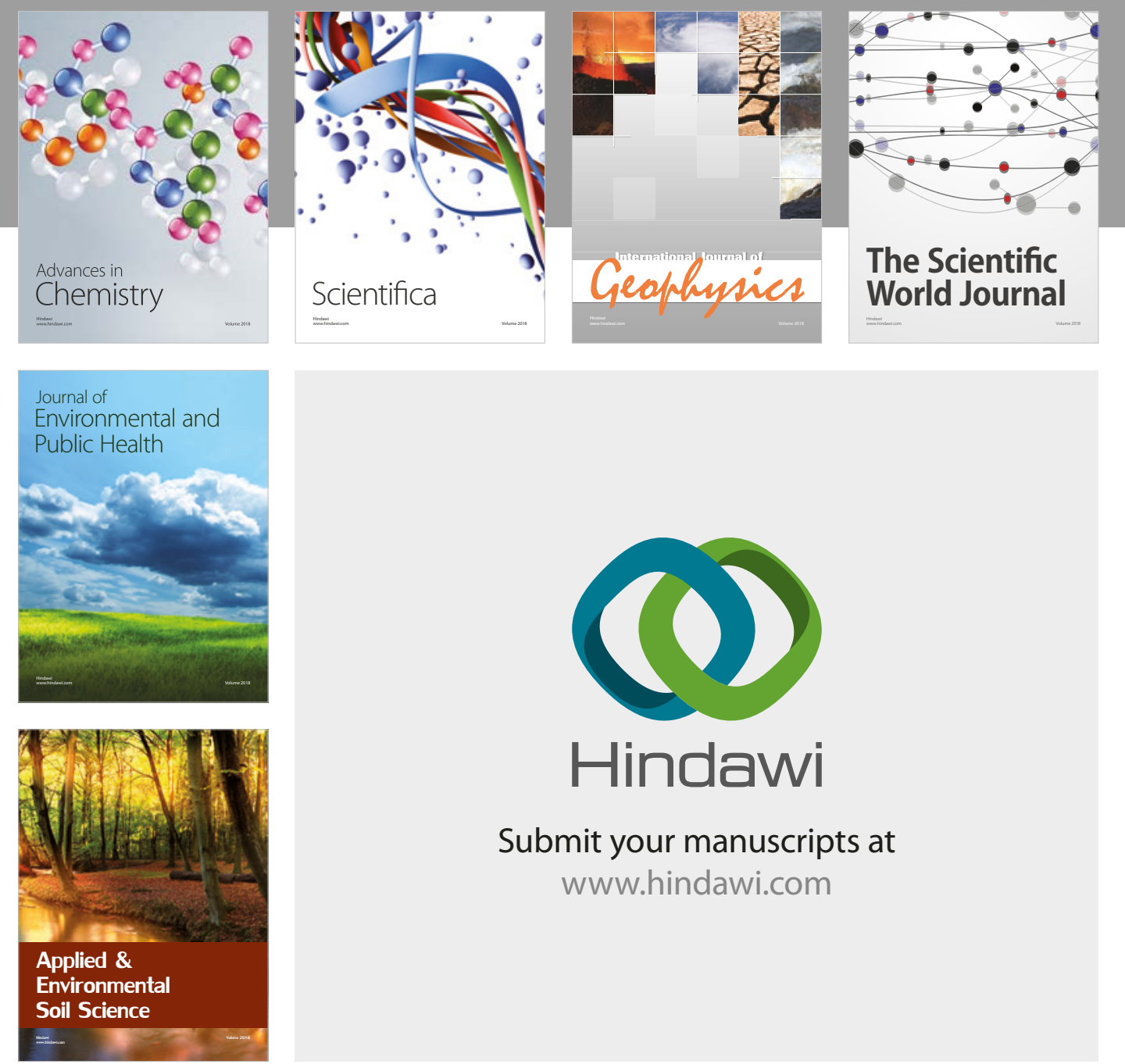

The Scientific

\section{World Journal}
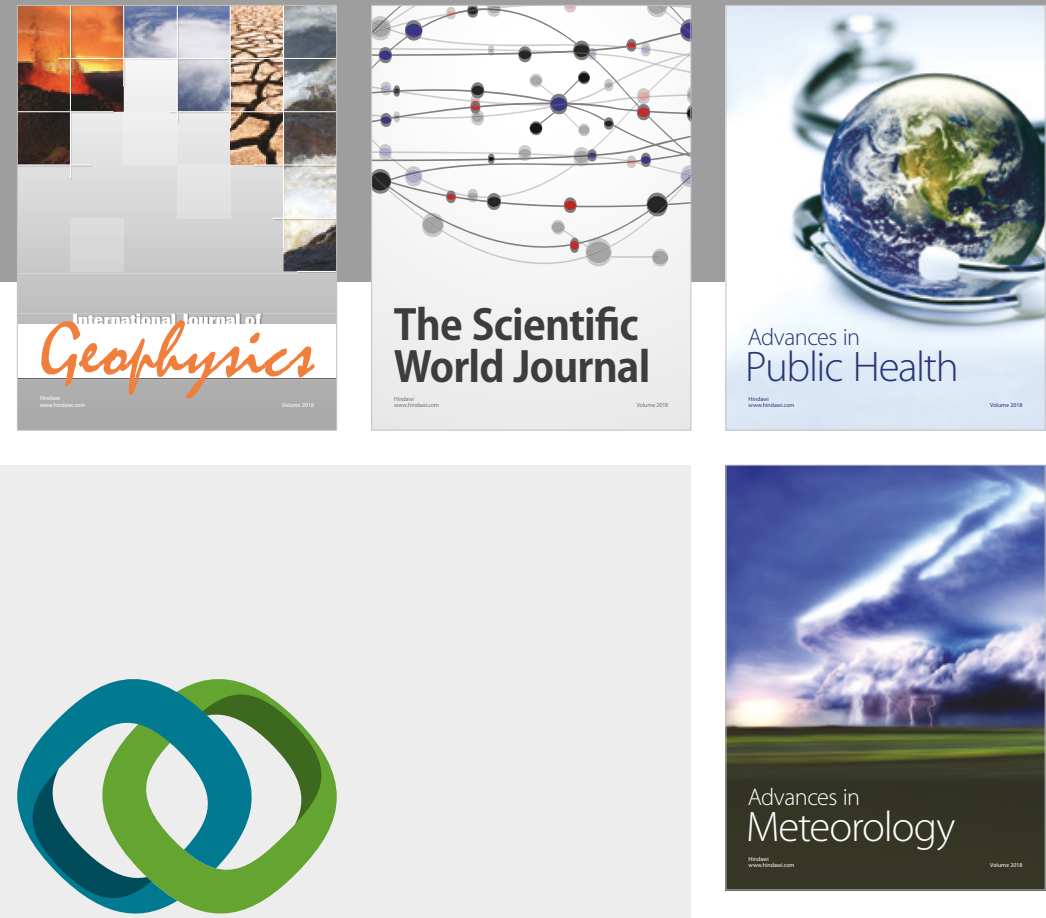

Advan

Public Health

\section{Hindawi}

Submit your manuscripts at

www.hindawi.com
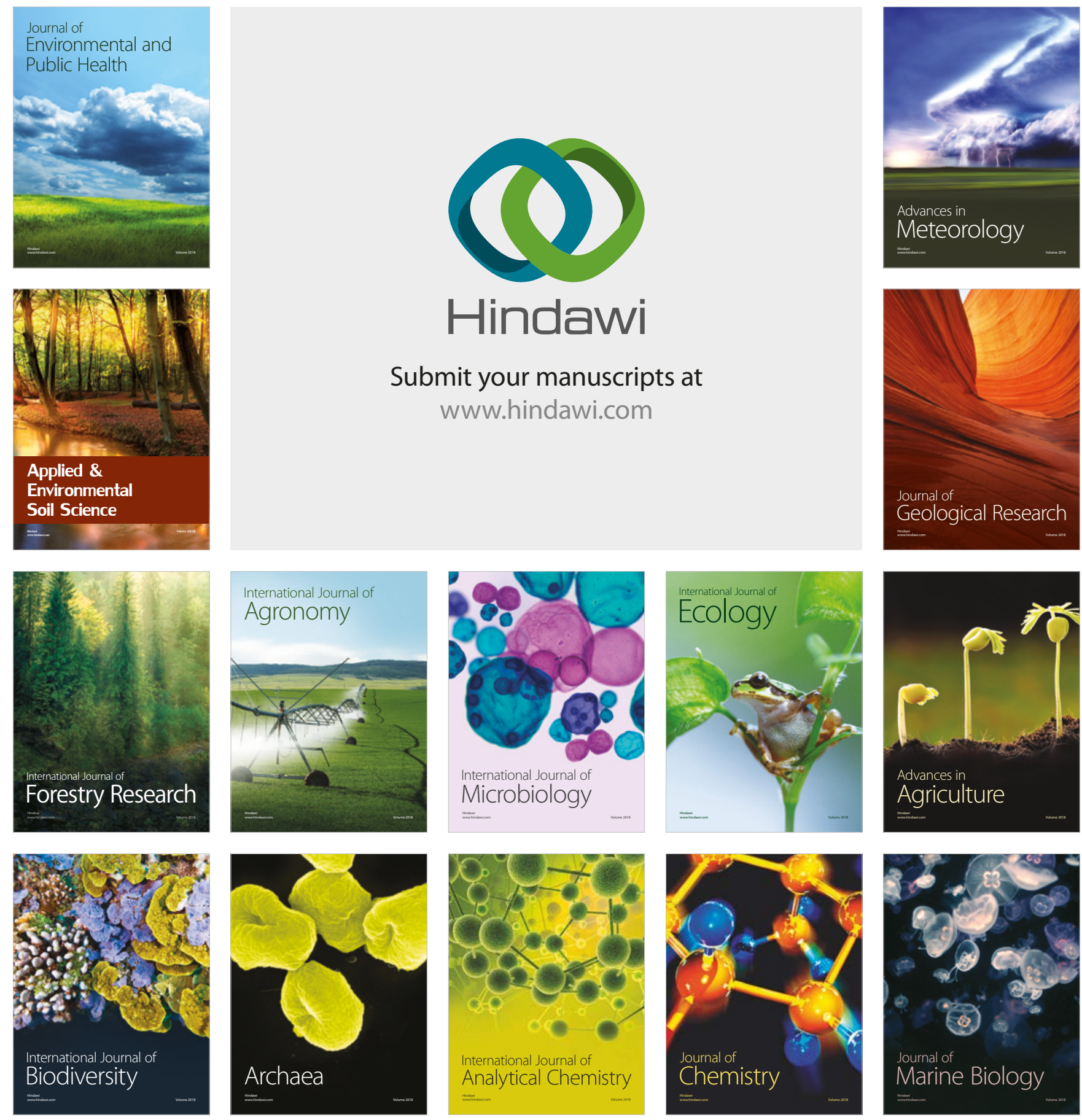